\title{
e-Health in Bangladesh: Current Status, Challenges, and Future Direction
}

\author{
Md. Rakibul Hoque \\ Center for Modern Information Management \\ Huazhong University of Science and Technology, Wuhan, 430074, China. \\ Email: rakibulmisdu@gmail.com \\ Md. Fahami Ahsan Mazmum \\ Department of Management Information Systems, University of Dhaka \\ Dhaka-1000, Bangladesh \\ Email:fahami_mis@yahoo.com \\ Yukun Bao* \\ Center for Modern Information Management \\ Huazhong University of Science and Technology, Wuhan, 430074, China. \\ Email:yukunbao@hust.edu.cn
}

\begin{abstract}
e-Health has enormous potential to ensure healthcare quality, accessibility, and affordability in developing countries. The application of information and communication technology to healthcare, especially e-Health, is rapidly advancing in Bangladesh. Both the public and private sectors have contributed to the development of the eHealth infrastructure throughout the country. The current status of e-Health in Bangladesh, however, has not been assessed. In the present study, we explored the current status of e-Health in the public and private sectors, as well as the technical and managerial challenges facing e-Health projects in Bangladesh. Our findings revealed that although e-Health in Bangladesh remains somewhat problematic, the difficulties could be overcome. Based on the current scenario and challenges of e-Health, the scope of some fields requires further improvement. The finding of this study will help policymakers to make effective decisions regarding e-Health services.
\end{abstract}

Keywords: e-Health, Current Status, Challenges, Bangladesh.

\section{Introduction}

Over the past decade, the rapid advancement in information and communication technology (ICT) has experienced tremendous change in health sector in many countries. Recent evidence suggests that e-Health is the blessing of ICT and is probably the most prominent service that has a noticeable effect on the development of healthcare sector in developing countries. $^{1,2,3}$ Government in developing countries put much hope in e-Health systems due to improve the quality and access to health services. ${ }^{4}$ Research on the adoption of e-Health in developing countries has shown that e-Health can be one solution to provide better access to healthcare facilities for patients, physician, nurses and other healthcare staffs, increase care quality and improve collaboration. ${ }^{5}$ Like developed and other developing countries, Bangladesh is beneficiary of the ICT based health service.

*Corresponding author: Tel: +86-27-87558579; fax: +86-27-87556437.

Email: yukunbao@hust.edu.cn or y.bao@ieee.org 
Bangladesh is one of few countries in the world where public hospitals offer free medical services to the citizen at the community level. Currently, there are 593 government hospitals, 467 upazila and union levels hospitals and 126 secondary \& tertiary levels hospitals in Bangladesh. Furthermore, 2,983 private hospitals and 5,220 private diagnostic centers are continuously working to ensure the better health services in Bangladesh. ${ }^{6}$ However, Bangladesh has been identified as one of 57 countries in the world with a critical shortage in health workforce (doctors, nurses and midwives number below 2.28 per 1000 population) and number of bed (4 per 10,000) in hospitals. ${ }^{7}$ In addition, providing affordable and adequate health care is a challenge due to poor healthcare infrastructure and high population density. ${ }^{8}$ In the light of these problems, the government has started a new era in the health sector by introducing Information and Communication Technology (ICT) for health service delivery.

More recently, e-Health is being given special emphasis due to the Digital Bangladesh campaign of the present government, which gives special preference to delivery of health services to citizens through ICT. The Ministry of Health \& Family Welfare has taken various steps to develop e-Health services as part of the current government's commitment to build a digital Bangladesh. $^{9}$ It has established a Management Information System (MIS) department under the Directorate General of Health Services (DGHS). The purpose of this department is to ensure the best use of ICT to build and maintain nationwide health information system as well as e-Health systems in Bangladesh. Government has made partnership with development partners, private organizations, and NGOs to improve the quality, efficiency and safety of e-Health services in Bangladesh. ${ }^{7}$ Different private healthcare organization has tried their best to provide the better services to their patient along with government through ICT enable health services.

Most previous studies have only focused on the application of e-Health in Bangladesh like mobile health, telemedicine, electronic patient record etc. No previous study has investigated the current status of eHealth in Bangladesh. In addition, no one assess the effectiveness of e-Health project and challenges faced by e-Health project in Bangladesh. Therefore, this study will fill the gap by evaluating the current status of eHealth initiatives in government and private sector of
Bangladesh. The main objective of this study is to describe and evaluate the current status of e-heath in Bangladesh. This study also analyzes the challenges in carrying our e-Health projects in Bangladesh, followed by recommendation.

The rest of the paper is organized as follows. Literature review is presented in Section 2. Section 3 explains briefly the e-Health initiatives in Bangladesh, while Section 4 identifies the challenges of e-Health implementation. We present the recommendation in Section 5. Finally, conclusion of this work is presented in Section 6.

\section{2. e-Health}

e-Health comprises a set of different concepts, including health, commerce and technology. ${ }^{10}$ It is generally understood to be the application of computer, Internet, mobile phone and other technologies to improve the patients' health status. ${ }^{11}$ The World Health Organization (2003) defines e-Health as "being the leveraging of the information and communication technology (ICT) to connect providers and patients and governments; to educate and inform healthcare professionals, managers and consumers; to stimulate innovation in care delivery and health system management; and, to improve our healthcare system". ${ }^{12}$ The Directorate General of Health Services (DGHS), Bangladesh explain the term "eHealth" as delivery of health services to citizens through the use of information and communication technology. ${ }^{13}$

Traditionally, e-Health is the delivery of health care with the support from different types of communications technologies, such as telemedicine, internet, electronic health records, mobile technology and clinical decision support. It is a service that is provided by using health information technology, computer, internet and related component. ${ }^{14}$ E-Health is the application of advanced ICT, such as the Internet, wireless and other sophisticated devices to provide health care delivery to patients. ${ }^{15}$ It involves the use of information technologies to improve health in general and the healthcare system in particular.

E-Health covers a wide range of medical informatics applications, both specific (for example, citizen health information) and general (for example, management systems, health-care services provision, etc.). But the importance of e-Health and the use of the Internet differentiate e-Health from traditional medical informatics. $^{16}$ It is increasingly employed in 
combination with tools that build capacity and address the quality of health care. ${ }^{17}$

\section{Current Status}

In fact, the e-Health initiative in Bangladesh began in 1998 when the Ministry of Health \& Family Welfare (MOHFW) undertook the Health \& Population Sector programs (HPSP) to enhance efficiency of program implementation. e-Health is being given special emphasis due to the Digital Bangladesh campaign of the present government, which gives special preference to delivery of health services to citizens through ICT. Different public \& private hospitals, NGOs and private organization introduced a number of e-Health programs and services in the health sector of the country. ${ }^{18}$

\subsection{Policy Initiatives}

The government of Bangladesh has taken a program for initiating improved e-Health for enduring quality health. In 2011, the Government of Bangladesh approved the 5year long Health, Population and Nutrition Sector Development Program (HPNSDP) 2011-2016 for Ministry of Health and Family Welfare (MoHFW). The HPNSDP 2011-2016 comprises 32 operational plans, of which one is the e-Health. ${ }^{19}$ The government's strategic policy guidelines for 'Digital Bangladesh' were highly appreciated by the global \& national experts and one of its stated objectives is that: "Quality healthcare will be provided to all citizens through innovative application of ICT", ${ }^{20}$

\section{2. e-Health Initiatives in Government Hospitals}

The Government of Bangladesh has a wide range of specific programs to gradually improve the e-Health infrastructure and its use in the country. Currently, health service through internet, health service through mobile phone, telemedicine service, complaintssuggestions through SMS, pregnancy care advice through SMS, online population health registry, GIS in health service, bulk SMS are available in government hospital in Bangladesh. ${ }^{19}$

In April 2009, Management Information System (MIS) in Directorate General of Health Services (DGHS), Bangladesh has established the Internet connectivity across all health points down to the upazila level. Recently, this network is expanded to all the union health centers and community clinics. The community clinics and union health centers have laptop computers and internet connection to provide e-Health services to the patients. Moreover, android tablets have been given to the community health workers to ensure better e-Health services in Bangladesh. This network will be the largest video-conferencing network for eHealth in Bangladesh. ${ }^{13}$

In May 2009, mHealth (Health Service through Mobile Phone) was established by ministry of health in each of all upazila hospitals and district hospitals of the country. It has been provided a mobile phone to act as a local call center for delivering medical advice as 24/7 basis to the citizens. mHealth service has created opportunity, mainly for poor people living in rural areas, to get medical advice. Medical advice is now also available for people live in long distance from hospital and late night. ${ }^{21}$

The innovative bulk SMS system was introduced in 2009. The use of bulk SMS was frequent and demanddriven. Mobile phone numbers of all health managers and staff were collected and grouped in this system. Customized text messages can be broadcast to one or multiple groups instantly. ${ }^{22}$

In 2009, Health ministry of Bangladesh undertook a pilot program in Nilphamari district of Bangladesh to see whether Geographical Information System (GIS) can be introduced in health sector through the existing information staff for mapping of health facilities and services. The pilot program was highly successful, and the report was highly appreciated by policy-makers. Being inspired from this pilot, each divisional and district health office has been provided with a GIS device called global positioning system (GPS). It helps in disease surveillance and also in mapping service availability. $^{23}$

In March 2010, Pregnancy Care Advice through SMS has launched in Bangladesh. This service is expected to contribute to achievement of MDG (Millennium Development Goal) 4 and 5 through improving neonatal and maternal health. The USAID is providing the initial seed-money to develop this service. $^{24}$

The telemedicine service in eight hospitals was formally inaugurated on July 6, 2011 from the National Digital Innovation Fair. In 2012, ten more telemedicine centers in 10 different hospitals were opened. In 2013, another 10 new telemedicine centers were established in 10 different hospitals. Therefore, current number of telemedicine centers is 28. Each of the hospitals has a 
mobile phone which an on-duty doctor carries. ${ }^{6}$ The Access to Information (A2I), winner of World Summit on Information (WSIS) Prize 2014, under the Prime Minister's Office operates Union Information and Service Centers (UISCs) in 4,547 unions of Bangladesh. Telemedicine service has been started in 30 UISCs on pilot basis. It is one of the most popular value added services, mainly for rural people, in respective UISCs. Doctors are giving medical consultation in every working day. ${ }^{25}$

An exciting and effective innovation has been added to the existing e-Health service is complaint-suggestion by through SMS. Display boards, describe how to send complaints by SMS for improving service, were added in 800 public hospitals. Patients and all people visiting the hospitals can send SMS if they are not satisfied with the service. These SMS come to a web portal and assigned staffs oversee the complaints. ${ }^{26}$

One of the City Corporations of Bangladesh (Rajshahi) introduced an Electronic Birth Registration System (EBRS) that provides citizens a machinereadable electronic card to update and retrieve demographic, schooling and immunization records. The card works as an incentive because without producing the card, citizens do not get healthcare, immunization, primary education or other city-corporation services. ${ }^{18}$

A draft of the Medical Biotechnology (MBT) law has been prepared. Ministry of health is working to strengthen medical biotechnology laboratories in 8 medical colleges. Medical biotechnology is often termed as the technology of the future, which applies the techniques of genetic engineering to modify biological organisms. It's implication in the economic, health and livelihood improvement is expected to be unparalleled. ${ }^{27}$

Making a permanent online Electronic Health Records (EHR) of all citizens of Bangladesh is now on progress. The goal of maintaining integrated health record for a patient is to enable care providers to improve their service quality. The project included the rural citizens, who represent $76 \%$ of the country's population, first. To equip the health facilities, health workers and community clinics, appropriate devices and Internet connectivity are being provided to these facilities aimed to be completed by $2016 .^{28}$

With technical assistance from DFID, a software consortium comprising both local and non-local IT houses is now engaged in developing integrated national
e-Health Enterprise Architecture (eHEA). The data collected on 120 million rural citizens, using machinereadable paper forms are now towards completion of digitization in searchable database format. These data, which comprise basic health-records of the citizens, will make the foundation of future lifetime shared health records. $^{29}$

The ministry of health and family welfare in Bangladesh is jointly planning with the World Bank to automate over 300 public hospitals. One government clinic (Bangladesh Secretariat Clinic) is already transformed into an automated system. In 2012, three hospitals have been included for automation. These hospitals are National Institute of Kidney Diseases \& Urology (NIKDU), Government Employees’ Hospital and Azimpur Maternity Hospital. Gradually all hospitals will be automated. ${ }^{13}$

\section{3. e-Health Initiatives in Private Hospitals}

Currently, most of the private clinics and hospitals in the Dhaka city are using their own database system for patient health records. Apollo Hospital, Square Hospital, United Hospital, Medinova hospital and Popular diagnostic center are using their own database system for patient health records to keep it for their future purpose to find out patient previous health records easily.

The Apollo Hospitals Dhaka (AHD) is a joint project of Apollo Hospitals India and STS Holdings Limited. The hospital is a showcase of synergy of medical technology and advances in IT through paperless medical records. It uses RFID (Radio Frequency Identification) that enables it to track the real time movement of high value assets, patients and staff. It has introduced tele-Health to create a connected community encompassing the patient, family and clinicians for improved outcomes, greater convenience and less expense for all. ${ }^{30}$

The health information systems of Square Hospital and United Hospital are quite similar. Both the hospitals maintain its own database systems for it's patients. This has added a new dimension to the development and communication of both the hospitals. Medinova Hospital has been operating a telemedicine service since 2007 by connecting patients through video conferencing with physicians in India as follow up of treatment or assessment. BIRDEM hospital has started automation of health services by efficient queue management, 
evaluation of patients, updated nursing service, integration of laboratory and pharmacy etc. ${ }^{31}$

The telemedicine system installed at CRP (Centre for the Rehabilitation of the Paralysed) in July 1999 was the first of its kind in Bangladesh. This was made by the support of the Swinfen Charitable Trust in the UK. CRP have access to consultants from the Royal Hospital, Haslar, in the UK with a variety of specialties who are agreed to provide consultation at free of cost. Moreover, consultants within Bangladesh are also invited to provide tele-medical consultation for their patients through the telemedicine link at CRP. ${ }^{32}$

\section{4. e-Health Initiatives in Private Organizations and NGOs}

NGOs, private organization and Mobile Phone Companies are also providing e-Health services to the patients in different areas in Bangladesh.

In October 2010, BIID launched e-Clinic service as pilot basis in Shoronkhola, Bagerhat \& Kaliakair, Gazipur and now rolled out in 10 locations. E-Clinic is basically an ICT enabled healthcare service and management facility by utilizing modern technology and telecommunication facilities. The e-Clinic offers quality health care, information and advisory services for the underprivileged communities in rural settings. ${ }^{33}$

D.Net (Development Research Network) is providing e-Health services through their tele-centers. A tele-Health employee (generally a female information worker called mobile Lady) moves from door-to-door and connects the otherwise out-of-reach families with quality health service via mobile communication to their head office in Dhaka, where doctors are available round-the-clock. ${ }^{34}$

Telemedicine Reference Centre Ltd. (TRCL) is one of the longest serving companies in telemedicine sector and had initiated its "Mobile Health" division in 2003. TRCL m-Health program is an extension of its electronic health platform designed for health system based medical services. As a result, TRCL itself is a solution provider as well as healthcare service provider. $^{35}$

The BRAC Manoshi project empowers community health workers with simple mobile phones for gathering patient information in real time and prioritizing treatments (e.g. for high-risk pregnancies), as well as for early intervention and emergency treatment for complications in delivery through remote consultation from stationed doctors. This is a five year urban maternal, neonatal and child health programme. ${ }^{36}$

The Health and Demographic Surveillance System (HDSS) by the International Centre for Diarrhoeal Disease Research, Bangladesh (ICDDR, B) currently covering 149 villages is one of the major components of this field program. HDSS includes data such as registration of births, deaths, migration and other sociodemographic and economic events. ICDDR, B made an e-data repository for the period beginning from 1975, which is being updated continuously. Recently ICDDR, B published a Microsoft Excel Workbook with information from HDSS of Matlab to freely distribute amongst the interested researchers, scientists, development activists and academics. ${ }^{37}$

"Aponjon" ("the close/dear one" in bangla) is a brand of mHealth service through mobile phones for expecting and new mothers in Bangladesh under the auspices of Mobile Alliance for Maternal Action (MAMA). Aponjon service was launched in September, 2011 with about 1500 subscribers on a pilot basis. In December 2012, Aponjon launched its service nationwide in Bangladesh, and women across the country are able to register. Aponjon aspires to reach more than 2 million mothers by 2015. In future, Aponjon plans to deliver the messages in dialects that differ significantly from the standard Bangla language spoken across the country. Aponjon services are operated under the program agreement between the governments of USA and Bangladesh. ${ }^{38}$

GrameenPhone, the largest mobile operator in Bangladesh received the GSM Association's Global Mobile Award 2007 in the category of "Best Use of Mobiles for Social and Economic Development" for its popular people-centric project "HealthLine". HealthLine is a medical call center where any person can call a mobile hotline through Grameen's mobile phone and consult a doctor on $24 / 7$ basis. The call is charged at a minimal rate per minute. More than two million people, mostly women, from the remotest part of Bangladesh used the system in the last 14 months. ${ }^{39}$

Banglalink has launched healthlink service for its customers to provide innovative and convenient health services. Through this service, banglalink subscribers will now be able to get health counseling services through third party (managed by synesis IT) call center. ${ }^{40}$ Similar services are offered by Robi. All Robi Customers can dial 789 and get connected to live call 
center agents who will be answering their health related queries and questions (from 8 am to $7 \mathrm{pm}$ ). ${ }^{41}$

A group of responsible physicians, telecom and Information and Communication (ICT) specialist and eminent persons have come together and formed a common platform named Bangladesh Society for Telemedicine \& e-Health (BSTeH). BSTeH's purpose is to promote e-Health, and telemedicine services in Bangladesh. BSTeH observed some research works about the health sector and acceptability of telemedicine and e-Health facilities in Bangladesh. ${ }^{31}$

\section{Challenges}

\subsection{Inadequate ICT Infrastructure}

Bangladesh has no adequate ICT infrastructural support such as Computers, Internet network, Printers, and electricity for e-Health. Moreover, only few percentage of the total population have access to computers. ${ }^{42}$ According to Bangladesh Telecommunication Regulatory Commission report only 4.5 percent people use internet among the total population. ${ }^{43}$ Internet access cost is also high and highly unreliable in Bangladesh. In addition, power supply is not enough and available to support e-Health activities. On the other hand, the time gap between the acquisition of the hardware and development of the custom software is so large that by the time software is ready for use, the hardware becomes obsolete. ${ }^{44}$

\subsection{Financial Problems}

The procurement, implementation and use of e-Health systems are expensive. ${ }^{28}$ According to world health organization (WHO), lack of funding is one of the key obstacles affecting e-Health adoption in developing countries. ${ }^{45}$ Bangladesh is not an exception. Most of the times, government has to depend on developed countries, foreign investors or World Bank for implementing large project. ${ }^{44}$ Researchers have found that fund is a major challenge regarding the adoption of e-Health systems in low income countries like Bangladesh. $^{46}$

\subsection{Resistance of Change}

Older administrative staff in hospital sectors of Bangladesh is familiar with manual system and nobody wants to implement new ideas in an old setup. This lack of motivation is a well-documented challenge, typically described as resistance to change ${ }^{47}$ or reluctance to new technology. ${ }^{48}$ There are a number of reasons why administrative staff, policy maker, physician and nurses resist the use of e-Health. Some of the primary reasons are (1) they fear that computerization of different healthcare activities may make some people redundant; (2) they are resistant to any kind of change in their familiar working environment. ${ }^{42}$ Researcher found that the very little use of e-Health at the hospitals and many physicians were skeptical of using e-Health systems. ${ }^{28}$ Staff also felt a lack of motivation and encouragement regarding introducing and adopting new ICTs.

\subsection{Usability \& User Acceptance}

Service provider in Government sector in Bangladesh has good knowledge on e-Health applications. But service recipients are not well-known with e-Health. So their perception about e-Health is not in fine condition. Users not trusting using an e-Health for documenting patient information will negatively influence the will to adopt and use an e-Health. Majority of the people in Bangladesh are unaware about the e-Health service. Only few portions of the people are using the e-Health services. Moreover, most of the people have not enough knowledge of using computers, internet or electronic service delivery. With $45.3 \%$ functional literacy rate ${ }^{49}$ and majority of the population based in rural areas, the people of Bangladesh predominantly rely on traditional and relatively low-tech ICT options to have access to health related information. In the ICT Development Index released by the International Telecommunication Union (ITU), Bangladesh is ranked is still not encouraging yet. Rank of Bangladesh is 138 out of 154 countries, only above Nepal. ${ }^{50}$

\subsection{Lack of Policy and Regulation}

Healthcare is a sensitive domain where people's lives are at risk. If some system is going to be used, proper procedures and rules are needed to be devised and followed to ensure safe practices of healthcare services otherwise it could lead to serious consequences. Although the government of Bangladesh adopted a national ICT policy in 2009, it has not yet had any effect on hospitals. The regulatory/legal framework in Bangladesh has not yet been modernized to accommodate the growing needs of the electronic 
world. Still, an e-mail has no official value and cannot be legally considered an acceptable mode of communication in government offices. There are no strong laws to protect against cyber-crime and laws for electronic authentication. ${ }^{42}$

\subsection{Interoperability of Systems}

Most of e-Health systems in developing countries are isolated because systems developed by different vendors of software, universities, firms and research institutions. $^{51}$ Interoperability between multiple heterogeneous systems and compatibility between various platforms and software packages is crucial for a fully functional "fit for purpose" e-Health to facilitate the electronic exchange of health information between disparate systems to enable the delivery of safe and effective patient care. Bangladesh government did not design any central database for citizen's access using through internet. Even there is no available information of any citizen in government hospitals to use any emergency healthcare situation. For this reason physician in government hospital face many difficulties to identify the patient and their healthcare needs. ${ }^{44}$

\section{Recommendation}

Adoption of e-Health is in its nascent stages in Bangladesh. For this reason development of local eHealth solutions, research on adoption, studies on usability should be more important.

Having a policy in theory is not enough, implementing rules and policies are needed. The importance of legal support, national standards and policies are also a great concern in the various study reported by some researchers. ${ }^{51}$ Rules and regulations are important for a new system or current system more thoroughly. ${ }^{52,53}$ It has been argued that starting point in adoption of e-Health is the development of national policy. ${ }^{54}$ The policymaker and government in Bangladesh should develop comprehensible national eHealth policy and strategies to enable the acceptance of e-Health.

Most of the physicians and nurses are not familiar with e-Health and the benefits they might bring. There is a need for training concerning the use of e-Health systems. Training for doctors, nurses, even patients are necessary in familiarizing with e-Health and breaking their fears. The training programs should be need-based and arranged during the implementation phase of an eHealth project in any public and private hospitals. ${ }^{42}$

e-Health systems should be easy to use and ease to navigate. Systems need to be customized to meet the specific demand of the patients. Moreover, there is a need to raise awareness of e-Health systems in different public and private hospitals. Successful project means involvement of all stakeholders in e-Health project. Without the involvement of user it will not be a successful project. So, government should take some steps to motivate the citizen to use e-Health services in their daily life. Government, private organization and NGOs can arrange different types of seminar, symposium, showing short films and broadcasting advertisement in radio and Television.

Information and communication technology infrastructure is an important component to implement e-Health in any country. Bangladesh should build ICT infrastructure step by step till village level to make the successful implementation of e-Health. Internet connection in village level is very important. Government should encourage different private companies and NGO to build ICT infrastructure for their e-Health service and provide e-Health from urban to rural areas.

The Management Information System (MIS) of DGHS has already taken an initiative to develop interoperability framework. ${ }^{19}$ They should implement eHealth standards and inter-operability framework for use in the database systems developed within short period of time. Final guideline should be prepared as early as possible which describes the standards and inter-operability procedures of the Health Information Systems Architecture. Health care organizations, development partners, NGOs, and private organizations will also be benefited from the inter-operability framework.

It is advisable for all kind of health care institution to keep the electronic patient record to provide faster and quality health service to patient. ${ }^{55,56}$ Electronic health records can help all stakeholder involved in health care delivery to store, communicate, and process of medical information. ${ }^{57}$ It is feasible first step in the context of developing countries. Health care service provider can use the database of voter list of Bangladesh with adding some additional information. Urban based doctors specialized are in a good position to incorporate ICT or health record in their practice in rural areas. 
Security and privacy is the major concerned in all aspect of e-Health in developing countries. ${ }^{58}$ There must be specific privacy regulations on the practice of eHealth so that patients can feel secure in the discloser of their personal information. ${ }^{2}$ Equipped with RAID servers, firewalls, VMware, underground cable system, automatic fire protection, and humidity control, four tiers of power supply system, antispy and antihacking system to prevent unauthorized entry, remote monitoring system, text alerts by mobile phone, etc., the data center should be improved with Internet bandwidth load management systems, new servers, additional storage, sever intelligence systems, etc. ${ }^{59}$

\section{Conclusion}

Health care sector in Bangladesh is undeveloped and information technology has not been introduced significantly to improve its quality of service. But the government is not in idle state. The government of Bangladesh has taken massive plan to improve their health sector. Like many other initiative, government also develop e-Health systems. Private institutions including hospital, telecommunication organization, and NGOs are trying to provide different e-Health services to the citizen. Both government and private sector are committed to provide health service using ICT. One issue may be arisen that is the perception of the service recipient toward these services. The analysis shows that the overall situation of e-Health in Bangladesh is good but not adequate. The service recipients are not wellknown with these services. In this respect, it can concluded that service provider have to build a quality ICT based health service that must be easily and widely available throughout the country. Researcher can make research on application of e-Health in Bangladesh.

\section{Acknowledgement}

This research is supported by MOE (Ministry of Education in China) Project of Humanities and Social Science (Project No.13YJA630002), and a grant from the Modern Information Management Research Center at Huazhong University of Science and Technology (Project No. 2014AA043).

\section{Conflict of Interest}

There are no known conflicts of interest.

\section{Address correspondence to:}

Dr. Yukun Bao

Center for Modern Information Management

Huazhong University of Science and Technology

Wuhan, 430074, China.

Email: yukunbao@hust.edu.cn

\section{References}

1. Sharifi, M., Ayat, M., Jahanbakhsh, M., Tavakoli, N., Mokhtari, H., \& Wan Ismail, W. K. (2013). E-Health implementation challenges in Iranian medical centers: a qualitative study in Iran. Telemedicine and e-Health, 19(2), 122-128.

2. Nessa, A., Ameen, M., Ullah, S. Kwak, K. (2008). 'Applicability of Telemedicine in Bangladesh: Current Status and Future Prospects', The International Arab Journal of Information Technology (IAJIT), vol. abs/0911.1, no. 2, pp. 138-145,

3. Alvarez, R. C. (2002). The promise of e-Health - a Canadian perspective. Ehealth International , 1(1) doi:10.1186/1476-3591-1-4, 4.

4. Nyella E. \& Mndeme M. (2010). Power tensions in health information system integration in developing countries.: the need for distributed control, Electronic journal of information systems in developing countries , 43(4), 1-19.

5. Khalifehsoltani S. N. \& Gerami M. (2010). E-Health Challenges, Opportunities and Experiences of Developing Countries. presented at the International Conference on $e$ Education, e-Business, 2010. Sanya , China: (IC4E '10).

6. Health Bulletin (2013), Ministry of Health and Family Welfare, Government of the People's Republic of Bangladesh

7. World Health Organization (2012). World health statistics 2012. World Health Organization.

8. Mostafa, R., Ehsanur Rahman, G.M.A., Hasan, G.M., Kabir, A., Rahman, A. \& Ashik, S. (2010) Proposed Deployments to Provide E-Healthcare in Bangladesh: Urban and Rural Perspectives. 12th IEEE International Conference on e-Health Networking Applications and Service

9. BDF (2010). Digital Bangladesh for Good governance, Bangladesh Development Forum, The Government of the People's Republic of Bangladesh

10. Oh, H., Rizo, C., Enkin, M., \& Jadad, A. (2005) 'What is eHealth?: a systematic review of published definitions'. World Hospital Health Service, 41(1), 32-40.

11. Broderick, M., \& Smaltz, D.H. (2003). E-Health Defined. HIMSS E-Health SIG White Paper. Retrieved October 11, 2009 from www.himss.org/content/files/ ehealth_whitepaper.pdf

12. World Health Organization (2003). Eastern Mediterranean Region health observatory', http://www.emro.who.int/ehealth

13. DGHS (2012) Directorate General of Health Services (DGHS) http://dghs.gov.bd/bn/licts_file/ images/ eHealth/ our_eHealth_Aug_2012.pdf

14. Ticia, G., Veronica, O., Karl, B., \& Ariel, P.-M. (2010). An Agenda For Action On Global E-Health,. Health affairs, 29, no.2 , 233-236. 
15. Ikhu-Omoregbe N. A, Ehikioya S. A, and Ayo C. K (2007). Implementing Operations Supports in e-Health Based Systems", Proceedings of International Conference on $3 G$ GSM, Covenant University, Ota, Nigeria.

16. Pagliari C. \& Sloan, D. G. (2005). 'What Is E-Health (4): A Scoping Exercise to Map the Field'. Journal of Medical Internet Research , 7(1) e9.doi:10.2196/jmir.7.1.e9.

17. Garrett, L., Chowdhury, M., \& Pablos-Méndez A, A. (2009). All for universal Health coverage (viewpoint). Lancet, 374: 1294-99.

18. Commonwealth, T. (2008). Library and Archive. from The Commonwealth: http://www.thecommonwealth.org/ files/178347/FileName/Bangladesh\%20Survey.pdf, Retrieved July 2, 2013.

19. DGHS (2012). Publication http://dghs.gov.bd/bn/ licts_file/images/ Health_Bulletin/ HB2012_CH/ HB2012_CH17_HIS-eHealth-MBT.pdf. Retrieved July 6, 2013, from Directorate General of Health Services

20. UNDP (2010). Strategic Priorities of Digital Bangladesh, Access to Information and United Nations Development Programme, October.

21. Ahmed, T., Bloom, G., Iqbal, M., Lucas, H., Rashed, S., Waldman, L., Khan, A. S., Islam, R, Bhuiya A., (2014). EHealth and M-Health in Bangladesh: Opportunities and Challenges, Institute of Development Studies

22. Health Bulletin (2012). Directorate General of Health Services (DGHS), http://dghs.gov.bd/bn/licts_file/ images/Health_Bulletin/HB2012_CH/HB2012_CH17_HISeH ealth-MBT.pdf Retrieved June 17, 2013, from

23. Afroz, T. (2012) 'Delivery of Mobile Phone Aided Health Services in Rural Bangladesh: A Study on Two Upazilas', Masters thesis, Department of General and Continuing Education, North South University, Bangladesh, http://mppgnsu.org/attachments/396_13.\%20Tahmina.pdf (accessed 28 November 2013)

24. DGHS (2011). e-Health (Hospital Automation). Retrieved June 29, 2013, from Directorate General of Health Services (DGHS): http://www.dghs.gov.bd/en/index.php/e-Health-icthealth-service/174-hospital-automation-process.

25. A2I (2013). Access to Information Programme (A2I) Evaluation Report, Access to Information Programme, Prime Minister's Office, Dhaka, Bangladesh

26. HIS, eHealth \& MBT (2012). Health, Population \& Nutrition Sector Development Program 2011-16, Health Information System (HIS) \& eHealth Operational Plan (ROP), Government of the People's Republic of Bangladesh

27. HPNSDP (2011). Health Population and Nutrition Sector Development Program (HPNSDP), 2011-16, Ministry of Health and Family Welfare, Bangladesh

28. Khan, S. Z., Shahid, Z., Hedstrom, K., \& Andersson, A. (2012). Hopes and Fears in Implementation of Electronic Health Records in Bangladesh. The Electronic Journal of Information Systems in Developing Countries.

29. Inayatullah S. and Shah, A (2011). E-Health Scenarios and Vision for Bangladesh Report, Dhaka, Bangladesh, The futurist, August

30. Haider, A. K. M. N.(2008). e-Health Initiatives, Apollo Hospitals Dhaka, Special contribution for this paper received 31. Debashsish D. (2010). Development of E-Health Application for Rural Community of Bangladesh. Journal of Theoretical and Applied Information Technology , 47-48.
32. Vassallo D., Hoque F., Roberts M., Patterson V., Swinfen P., and Swinfen R. (2001). 'An Evaluation of The First Year's Experience with a Low Cost Telemedicine Link in Bangladesh," Computer Journal of Telemedicine and Telecare, vol. 7, no. 3, pp. 125-138,

33. Nour, S. (2013). e-Clinic: Integration of ICT in Health Sector, Institute of ICT in Development (BIID), Bangladesh.

34. Uddin MF, and Hasan M (2008). Access to Health Information through Telecentre: D.Net's Experience from Pallitathya Model.

35. Zakir S (2008). eHealth initiatives and projects of Telemedicine Reference Center Ltd. (TRCL) Dhaka, Bangladesh, Special contribution

36. CHMI (2014). ICT in Health: Bangladesh is Moving Ahead, Center for Health Market Innovation

37. Commonwealth Business Council. (2011). Library: Report. Retrieved August 1, 2013, from Commonwealth Business Council (CBC): http://www.cbcglobal.org/ images/uploads/docs/EHealth.pdf

38. Aponjon (2013). Aponjon. Retrieved August 10, 2013, from About-Aponjon: http://aponjon.com.bd/ Content.php?MId=35\&SubMId=53

39. Grameenphone (2013). Health-Grameenphone Pilot TeleDermatology in Bangladesh. Retrieved August 11, 2013, from Grameenphone: http://www.grameenphone.com/aboutus/corporate-information/corporate-responsibility/health 40. Banglalink (2013). Information based health services from Banglalink: http://www.banglalinkgsm.com/en/ value_added_services/information_based_services/healthlink 41. Robi (2013). Value Added Services: Information Service: Health Tips \& Health Line. from Robi: http://www.robi.com.bd/index.php/page/view/452

42. Uddin, G (2012). E-governance of Bangladesh: Present Scenario, Expectation, Ultimate Target and Recommendation, International Journal of Scientific \& Engineering Research, Volume 3, Issue 11, November-2012 1 ISSN 2229-5518

43. BTRC (2014). Internet Subscribers in Bangladesh, Bangladesh Telecommunication Regulatory Commission Report

44. Alam, J. (2012). E-Governance in Bangladesh: Present Problems and Possible Suggestions for Future Development, International Journal of Applied Information Systems (IJAIS) - ISSN: 2249-0868 Foundation of Computer Science FCS, New York, USA Volume 4- No.8, December 2012 www.ijais.org

45. World Health Organization. (2010). Program and Project : Publication : Global Observatory for eHealth. Retrieved August 17, 2013, from World Health Organization: http://whqlibdoc.who.int/publications/2011/9789241564168_e ng.pdf

46. Fryatt, R., Mills, A., \& Nordstrom, A. (2010). Financing of health systems to achieve the health Millennium Development Goals in low-income countries. The Lancet, 375(9712), 419-426.

47. Khalifehsoltani, S.N. \& Gerami, M.R. (2010). E-Health Challenges, Opportunities and Experiences of Developing Countries International Conference on e-Education, $e$ Business, e-Management, and e-Learning, Sanya, China. 48. Fitzgerald, G., Piris, L. \& Serrano, A. (2008) Identification of Benefits and Barriers for the Adoption of E-Health 
Hoque et al.

Information Systems Using a Socio-Technical Approach. Paper presented at the 30th International Conference on Information Technology Interfaces, 2008, Cavtat, Croatia.

49. BANBEIS (2011). Bangladesh Bureau of Educational Information \& Statistics Report, Ministry of Education, Bangladesh

50. ITU (2010). ICT Development Index 2010, International Telecommunications Union

51. Gao, X., Xu, J., Sorwar, G. \& Croll P. (2013). Implementation of E-Health Record Systems and E-Medical Record Systems in China, The International Technology Management Review, Vol. 3 (2013), No. 2, 127-139.

52. Kimaro, H.C. \& Nhampossa, J.L. (2005) Analyzing the Problem of Unsustainable Health Information Systems in Less-Developed Economies: Case Studies from Tanzania and Mozambique. Information Technology for Development, 11, 3, 273-298.

53. Sahay, S. \& Walsham, G. (2006) Scaling of Health Information Systems in India: Challenges and Approaches. Information Technology for Development, 12, 3, 185-200.

54. Juma, K., Nahason, M., Apollo, W., Gregory, W., \& Patrick, O. (2012). Current Status of E-Health in Kenya and Emerging Global Research Trends.

55. Khalifa, M. (2013). Barriers to Health Information Systems and Electronic Medical Records Implementation. A Field Study of Saudi Arabian Hospitals. Procedia Computer Science, 21, 335-342.

56. Jha, A. K., DesRoches, C. M., Campbell, E. G., Donelan, K., Rao, S. R., Ferris, T. G., \& Blumenthal, D. (2009). 'Use of electronic health records in US hospitals'. New England Journal of Medicine, 360(16), 1628-1638.

57. Angst, C. M., \& Agarwal, R. (2009). Adoption of electronic health records in the presence of privacy concerns: the elaboration likelihood model and individual persuasion. MIS Quarterly, 33(2), 339-370.

58. Blobel B (2007). Comparing approaches for advanced eHealth security infrastructures. International Journal of Medical Informatics. Elsevier. Volume 76, Issue 5, Pages 454-459.

59. Li, F. (2012,). Study on security and prevention strategies of computer network. In Computer Science and Information Processing (CSIP), 2012 International Conference on (pp. 645-647). IEEE. 